\title{
Anesthetic Techniques and Complications for Airway Foreign Body Removal in Children
}

\author{
Marinov Ts. ', M. Belitova', T. Popov², J. Rangachev², \\ O. Stoyanov', D. Popova ${ }^{2}$ \\ 'Department of Anesthesiology and Intensive Care; University Hospital "Queen Giovanna" - ISUL; \\ Medical University - Sofia \\ 2Department of ENT Surgery; University Hospital „Queen Giovanna“ - ISUL; \\ Medical University - Sofia
}

\begin{abstract}
Theoretical basis: Aspiration of foreign bodies by children is a common problem around the world. Asphyxiation from inhaled foreign bodies is a leading cause of accidental death among children younger than 4 years. The Aim of the study is to determine different anesthetic techniques and complications for airway foreign body removal in children. Results: Most patients with aspirated foreign bodies are children younger than 3 years. Most of the aspirated foreign bodies are organic materials. Nuts (especially peanuts) and seeds (mainly sunflower and watermelon) are the most commonly aspirated foreign bodies reported in almost all studies. A history of a witnessed choking event is highly suggestive of an acute aspiration. Major iatrogenic complications were specified in 21 studies with 9437 children with aspirated foreign bodies. These complications included severe laryngeal edema or bronchospasm, pneumothorax, pneumomediastinum, cardiac arrest, tracheal or bronchial laceration, and hypoxic brain damage. Mortality data were obtained from 26 articles with 43 deaths among 10,236 children (0.42\%) with aspirated foreign bodies. Anesthetic considerations encompass preoperative assessment, management techniques for flexible or rigid bronchoscopy, and postbronchoscopic disposition. Conclusion: Aspiration of a foreign body is a potentially lethal event. Although several anesthetic techniques are effective for managing children with foreign body aspiration, there is no consensus from the literature as to which technique is optimal.
\end{abstract}

Key words: Foreign body, anesthetic techniques, complications.

\section{Literature review}

Aspiration of foreign bodies by children is a common problem around the world. Asphyxiation from inhaled foreign bodies is a leading cause of accidental death among children younger than 4 years. During the 19th century, treatment of foreign body aspiration by purges, bleeding, and emetics were largely ineffective. Mortality was estimated at $23 \%$. This rate plummeted with the development of bronchoscopic techniques for the removal of these foreign bodies. ${ }^{1}$

Most patients with aspirated foreign bodies are children younger than 3 years. Four series reported the median age, and 7 series reported the mean age of children with aspirated foreign bodies. The median and the mean age ranged from 1 to 2 years $s^{2,3,4,5}$ and from 2.1 to 3.8 years $^{2,6,7,8,9,10,11}$ respectively.

Most of the aspirated foreign bodies are organic materials. ${ }^{4,5,6,8,9,10,11,12,13,14,15,16,17,18,19,20,21,22,23,24 ~ N u t s ~}$ (especially peanuts) and seeds (mainly sunflower and watermelon) are the most commonly aspirated foreign bodies reported in almost all studies. A history of a witnessed choking event is highly suggestive of an acute aspiration. Data were available to determine the sensitivity, specificity, positive predictive value, and negative predictive value of a witnessed event in 10 studies. ${ }^{2,6,12,16,21,22,23,25,26,27}$ 
Children with aspirated foreign bodies typically present with the symptoms of coughing, dyspnea, wheezing, cyanosis, or stridor. Data were available in 10 studies to determine the sensitivity and the specificity of these presenting signs and symptoms. ${ }^{2,10,16,17,21,22,23,25,26,27}$ A history of cough is highly sensitive for foreign body aspiration but is not very specific. On the other hand, a history of cyanosis or stridor is very specific for foreign body aspiration but is not very sensitive. Signs and symptoms typical in delayed presentations include unilateral decreased breath sounds, persistent cough or wheezing, recurrent or nonresolving pneumonia, or rarely, pneumothorax.

While rigid bronchoscopy was used solely for the removal of foreign bodies in most studies, both flexible and rigid bronchoscopies were used in 4 series. ${ }^{2,5,16,28}$ A minority of foreign bodies were removed by flexible bronchoscopy in 3 of these studies, ${ }^{2,16,28}$ whereas Tang et al. ${ }^{5}$ reported successful removal by flexible bronchoscopy in $91.3 \%$ of children with foreign body aspiration. For this study, local anesthesia with sedation was used during bronchoscopy. For children undergoing rigid bronchoscopy, general anesthesia was used in all studies, and details regarding the anesthetic technique were provided in 12 studies. Preparation of the child for general anesthesia is a specific process. ${ }^{29}$ General anesthesia in children is characterized by specific risks. ${ }^{30}$ Both inhaled ${ }^{12,21,24,31}$ and $\mathrm{IV}^{15,28}$ inductions were reported. Similarly, anesthesia was maintained with either inhaled ${ }^{15,21,24,31}$ or $\mathrm{IV}^{16,27,32}$ drugs or a balanced anesthetic. ${ }^{28}$ Five studies reported the use of neuromuscular blockers. ${ }^{12,13,15,31,32}$ Bittencourt et al. ${ }^{13}$ and Hasdiraz et al ${ }^{15}$ used paralysis as needed during the procedure and attempted to maintain spontaneous ventilation when possible. On the other hand, Divisi et al. ${ }^{28} \mathrm{com}-$ mented that spontaneous ventilation is not suitable for rigid bronchoscopy because of resultant oxygen desaturation and used a balance anesthetic with sevoflurane and remifentanil. Shivakumar et al. ${ }^{10}$ used jet ventilation to prevent oxygen desaturation. None of the authors commented on using drying drugs such as glycopyrolate before bronchoscopy. Seven studies commented on using steroids for laryngeal edema, with the majority of those authors favoring steroid use only as needed, ${ }^{12,15,20,28,32}$ as opposed to routine administration. ${ }^{27,24}$ In 4 studies, antibiotics were given routinely preoperatively, ${ }^{15,27}$ postoperatively,,$^{24}$ or as a 5 -day course, ${ }^{20}$ whereas authors in 3 studies favored antibiotic administration only as needed for infection. . $^{1218,28}$

Major iatrogenic complications were specified in 21 studies with 9437 children with aspirated foreign bodies. These complications included severe laryngeal edema or bronchospasm, pneumothorax, pneumomediastinum, cardiac arrest, tracheal or bronchial laceration, and hypoxic brain damage. These major complications occurred in 91 of these 9437 children $(0.96 \%)$. Of the 11 cardiac arrests that were reported, 1 occurred after induction of anesthesia in a child who was hypoxic on admission, 5 occurred during bronchoscopy because of hypoxia (3) or bleeding (2), and the remaining 5 were not specified. Other reported serious complications included infection, bleeding, and failed bronchoscopic removal that necessitated thoracotomy or tracheotomy to remove the object. Mortality data were obtained from 26 articles with 43 deaths among 10236 children $(0.42 \%)$ with aspirated foreign bodies. Twenty-five deaths occurred in the 5 largest series with 5927 children $(0.42 \%)$. ${ }^{5,12,15,31,32}$

Anesthetic considerations encompass preoperative assessment, management techniques for flexible or rigid bronchoscopy, and postbronchoscopic disposition.

The preoperative assessment should determine where the aspirated foreign body has lodged, what was aspirated, and when the aspiration occurred. If the foreign body is located in the trachea, the child is at risk for complete airway obstruction and should be taken urgently to the operating room. Conversely, the risk of complete airway obstruction is less if the object is firmly lodged beyond the carina. It is important to determine the type of foreign body: Organic materials can absorb fluid and swell, oils from nuts cause localized inflammation, and sharp objects can pierce the airway. The time since the aspiration should be established because airway edema, granulation tissue, and infection may make retrieval more difficult with delayed presentations. A recently aspirated object may move to a different position with coughing. The time of the last meal should be established to assess the risk of aspiration. The airway patency should be assessed. If the patient is in severe distress, urgent bronchoscopy should be performed. If the patient is stable, however, some authors suggest that bronchoscopy may be performed during normal daytime operating hours to ensure optimal conditions with an experienced bronchoscopist and anesthesiologist. ${ }^{33}$ 
Because surgeon and anesthesiologist share management of a potentially obstructed airway, clear communication and good cooperation are essential. Before induction, a detailed anesthetic and operative plan should be discussed. The 3 main anesthetic issues involve the methods of induction, ventilation during bronchoscopy, and maintenance of anesthesia.

The choice of induction is dominated by the consideration of converting a proximal partial obstruction into a complete obstruction. The conversion from spontaneous negative pressure breathing to positive pressure ventilation theoretically risks dislodging an unstable proximal body, causing complete obstruction. ${ }^{34}$ Although hypoxic arrest during the initial stages of bronchoscopy is a recognized cause of death the relative contributions of obstruction on initial presentation, during the induction of anesthesia, and from dislodgement during bronchoscopy, are unclear from published accounts.

After induction of general anesthesia, the rigid bronchoscope is inserted through the glottic opening. The anesthesia circuit is connected to the sideport of the bronchoscope to allow ventilation. Both spontaneous ventilation and controlled ventilation are feasible for removal of foreign bodies. Spontaneous ventilation around the bronchoscope may be more suitable for removal of proximal bodies, during which leakage around the scope may make effective positive pressure ventilation difficult. Manually closing the mouth and nose can diminish a large leak around the scope and improve ventilation. Positive pressure ventilation down the bronchoscope, with intermittent apnea while manipulating the object, may be more suitable for distal retrieval. Because airway trauma and rupture are significant and potentially fatal complications, it is essential to avoid coughing and bucking secondary to the intense stimulation from a rigid bron- choscope deep in the bronchial tree. Movement can be prevented with neuromuscular blocking drugs ${ }^{34}$ or with a deep level of anesthesia. A prospective study of 36 children with aspirated foreign bodies found that controlled ventilation is more effective than is spontaneous ventilation. ${ }^{34}$ All children in the spontaneous ventilation group were switched to either assisted or controlled ventilation because of coughing and bucking.

Dropping the foreign body during retrieval is a potentially life-threatening complication. ${ }^{35,36}$ The vocal cords should be well relaxed, either by paralysis or an adequate depth of anesthesia before removal of the foreign body through the larynx. Dropping the foreign body has a higher correlation with the experience level of the bronchoscopist than with the mode of ventilation. ${ }^{36}$ If the object is dropped in the proximal airway and cannot immediately be removed, pushing it back into a bronchus can eliminate an obstruction. If a bronchial body falls into the other bronchus, there is potential for complete airway obstruction due to edema and inflammation at the original site..$^{35}$ In the setting of a marginal airway, optimization of other components of ventilation is essential.

After the extraction of the foreign body and the removal of the rigid bronchoscope, the choice of ventilation during emergence is influenced by pulmonary gas exchange and the degree of airway edema. For uncomplicated cases, spontaneous ventilation assisted by mask ventilation as needed may be adequate.

Aspiration of a foreign body is a potentially lethal event. Outcomes have improved over the years because of advances in anesthesia and bronchoscopy. Although several anesthetic techniques are effective for managing children with foreign body aspiration, there is no consensus from the literature as to which technique is optimal.

\section{References}

1. Clerf LH. Historical aspects of foreign bodies in the air and food passages. South Med J 1975; 68:1449-54

2. Cohen S, Avital A, Godfrey S, Gross M, Kerem E, Springer C. Suspected foreign body inhalation in children: what are the indications for bronchoscopy? J Pediatr 2009; 155:276-80.

3. Gregori D, Salerni L, Scarinzi C, Morra B, Berchialla P, Snidero S, Corradetti R, Passali D, Klaus A, Isidor H, Gernot S, Jan B, Bernard B, Karchev T, Tzolov T, Ranko M, Lana K, Ivo S, Mirko T, Caye-Thomasen P, Anne P, Volker J, Onder G, Simasko N, Matilda C, Christopoulos I, Pass ̃̃ li GC, Pass Ã li F, Damiani V, MieczysÅaw C, Dorin S, Gheorghe DC, Janka J, Miha Z, Ales G, Ales M, Lorenzo R, Javier C, Pontus S, Philippe P, Ahmed C, Metin OT, Ozden CA, Riza D, John G, Peter R, Rupert O. Foreign bodies in the upper airways causing complications and requiring hospitalization in children aged 0-14 years: results from the ESFBI study. Eur Arch Otorhinolaryngol 2008;265:971-8

4. Higuchi O, Adachi Y, Ichimaru T, Asai M, Kawasaki K. Foreign body aspiration in children: a nationwide survey in Japan. Int J Pediatr Otorhinolaryngol 2009; 73:659-61. 
5. Tang LF, Xu YC, Wang YS, Wang CF, Zhu GH, Bao XE, Lu MP, Chen LX, Chen ZM. Airway foreign body removal by flexible bronchoscopy: experience with 1027 children during 2000-2008. World J Pediatr 2009; 5:191-5.

6. Ciftci AO, Bingol-Kologlu M, Senocak ME, Tanyel FC, Buyukpamukcu N. Bronchoscopy for evaluation of foreign body aspiration in children. J Pediatr Surg 2003; 38:1170-6.

7. Emir H, Tekant G, Besik C, Elicevik M, Senyuz OF, Buyukunal C, Sarimurat N, Yeker D. Bronchoscopic removal of tracheobroncheal foreign bodies: value of patient history and timing. Pediatr Surg Int 2001; 17:85-7.

8. Mahafza T, Khader Y. Aspirated tracheobronchial foreign bodies: a Jordanian experience. Ear Nose Throat J 2007; 86:107-10

9. Roh JL, Hong SJ. Lung recovery after rigid bronchoscopic removal of tracheobronchial foreign bodies in children. Int J Pediatr Otorhinolaryngol 2008; 72:635-41.

10. Shivakumar AM, Naik AS, Prashanth KB, Shetty KD, Praveen DS. Tracheobronchial foreign bodies. Indian J Pediatr 2003; 70: $793-7$.

11. Tan HK, Brown K, McGill T, Kenna MA, Lund DP, Healy GB. Airway foreign bodies (FB): a 10-year review. Int J Pediatr Otorhinolaryngol 2000; 56:91-9.

12. Aydogan LB, Tuncer U, Soylu L, Kiroglu M, Ozsahinoglu C. Rigid bronchoscopy for the suspicion of foreign body in the airway. Int J Pediatr Otorhinolaryngol 2006; 70:823-8.

13. Bittencourt PF, Camargos PA, Scheinmann P, de Blic J. Foreign body aspiration: clinical, radiological findings and factors associated with its late removal. Int J Pediatr Otorhinolaryngol 2006; 70:879-84.

14. Brkic F, Delibegovic-Dedic S, Hajdarovic D. Bronchoscopic removal of foreign bodies from children in Bosnia and Herzegovina: experience with 230 patients. Int J Pediatr Otorhinolaryngol 2001; 60:193-6.

15. Hasdiraz L, Oguzkaya F, Bilgin M, Bicer C. Complications of bronchoscopy for foreign body removal: experience in 1,035 cases. Ann Saudi Med 2006; 26:283-7.

16. Heyer CM, Bollmeier ME, Rossler L, Nuesslein TG, Stephan V, Bauer TT, Rieger CH. Evaluation of clinical, radiologic, and laboratory prebronchoscopy findings in children with suspected foreign body aspiration. J Pediatr Surg 2006; 41:1882-8.

17. Kadmon G, Stern Y, Bron-Harlev E, Nahum E, Battat E, Schonfeld T. Computerized scoring system for the diagnosis of foreign body aspiration in children. Ann Otol Rhinol Laryngol 2008; 117:839-43.

18. Karakoc F, Karadag B, Akbenlioglu C, Ersu R, Yildizeli B, Yuksel M, Dagli E. Foreign body aspiration: what is the outcome? Pediatr Pulmonol 2002; 34:30-6.

19. Roda J, Nobre S, Pires J, Еstкvго MH, Fйlix M. Foreign bodies in the airway: a quarter of a century's experience. Rev Port Pneumol 2008; $14: 787-802$.

20. Shubha AM, Das K. Tracheobronchial foreign bodies in infants. Int J Pediatr Otorhinolaryngol 2009; 73:1385-9.

21. Skoulakis CE, Doxas PG, Papadakis CE, Proimos E, Christodoulou P, Bizakis JG, Velegrakis GA, Mamoulakis D, Helidonis ES. Bronchoscopy for foreign body removal in children. A review and analysis of 210 cases. Int J Pediatr Otorhinolaryngol 2000; 53:143-8.

22. Tokar B, Ozkan R, Ilhan H. Tracheobronchial foreign bodies in children: importance of accurate history and plain chest radiography in delayed presentation. Clin Radiol 2004; 59:609-15.

23. Tomaske M, Gerber AC, Stocker S, Weiss M. Tracheobronchial foreign body aspiration in children-diagnostic value of symptoms and signs. Swiss Med Wkly 2006; 136:533-8.

24. Yadav SP, Singh J, Aggarwal N, Goel A. Airway foreign bodies in children: experience of 132 cases. Singapore Med J 2007; 48: 850-3.

25. Ayed AK, Jafar AM, Owayed A. Foreign body aspiration in children: diagnosis and treatment. Pediatr Surg Int 2003; 19:485-8.

26. Erikзi V, Karazay S, Arikan A. Foreign body aspiration: a four-years experience. Ulus Travma Acil Cerrahi Derg 2003; 9:45-9.

27. Kiyan G, Gocmen B, Tugtepe H, Karakoc F, Dagli E, Dagli TE. Foreign body aspiration in children: the value of diagnostic criteria. Int J Pediatr Otorhinolaryngol 2009; 73:963-7.

28. Divisi D, Di Tommaso S, Garramone M, Di Francescantonio W, Crisci RM, Costa AM, Gravina GL, Crisci R. Foreign bodies aspirated in children: role of bronchoscopy. Thorac Cardiovasc Surg 2007; 55:249-52.

29. Б. Младенов. Подготовка на дете за анестезия. Практическа Педиатрия 06/2018; $14-18$.

30. Б. Младенов. Рискове при анестезия в детската възраст. Практическа педиатрия 06/2018; $10-14$.

31. Eren S, Balci AE, Dikici B, Doblan M, Eren MN. Foreign body aspiration in children: experience of 1160 cases. Ann Trop Paediatr 2003; 23:31-7.

32. Hui H, Na L, Zhijun CJ, Fugao ZG, Yan S, Niankai ZK, Jingjing CJ. Therapeutic experience from 1428 patients with pediatric tracheobronchial foreign body. J Pediatr Surg 2008; 43:718-21.

33. Mani N, Soma M, Massey S, Albert D, Bailey CM. Removal of inhaled foreign bodies-middle of the night or the next morning?. Int J Pediatr Otorhinolaryngol 2009; 73:1085-9.

34. Soodan A, Pawar D, Subramanium R. Anesthesia for removal of inhaled foreign bodies in children. Paediatr Anaesth 2004; 14:947-52.

35. Kumar S, Saxena AK, Kumar M, Rautela RS, Gupta N, Goyal A. Anesthetic management during bronchoscopic removal of a unique, friable foreign body. Anesth Analg 2006; 103:1596-7

36. Pawar DK. Dislodgement of bronchial foreign body during retrieval in children. Paediatr Anaesth 2000; 10:333-5.

\section{Correspondence to: \\ Tsvetomir Marinov, MD, PhD}

Department of Anesthesiology and Intensive Care

University Hospital ,Queen Giovanna“ - ISUL

Byalo More Str 8

Medical University - Sofia

E-mail: ts.marinov@abv.bg 